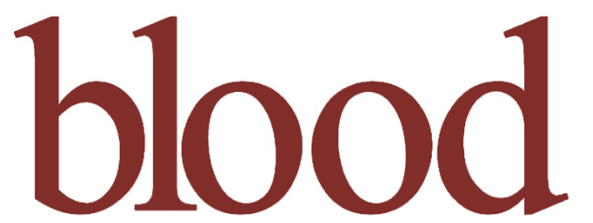

2002 100: 1662-1669

Prepublished online May 17, 2002;

doi:10.1182/blood-2002-02-0589

\title{
Sustained high-level expression of human factor IX (hFIX) after liver-targeted delivery of recombinant adeno-associated virus encoding the hFIX gene in rhesus macaques
}

Amit C. Nathwani, Andrew M. Davidoff, Hideki Hanawa, Yunyu Hu, Fredric A. Hoffer, Alexander Nikanorov, Clive Slaughter, Catherine Y. C. Ng, Junfang Zhou, Jay N. Lozier, Timothy D. Mandrell, Elio F. Vanin and Arthur W. Nienhuis

Updated information and services can be found at: http://bloodjournal.hematologylibrary.org/cgi/content/full/100/5/1662

Articles on similar topics may be found in the following Blood collections:

Gene Therapy (389 articles)

Hemostasis, Thrombosis, and Vascular Biology (2449 articles)

Information about reproducing this article in parts or in its entirety may be found online at:

http://bloodjournal.hematologylibrary.org/misc/rights.dtl\#repub_requests

Information about ordering reprints may be found online at:

http://bloodjournal.hematologylibrary.org/misc/rights.dtl\#reprints

Information about subscriptions and ASH membership may be found online at:

http://bloodjournal.hematologylibrary.org/subscriptions/index.dtl

Blood (print ISSN 0006-4971, online ISSN 1528-0020), is published semimonthly by the American Society of Hematology, 1900 M St, NW, Suite 200, Washington DC 20036.

Copyright 2007 by The American Society of Hematology; all rights reserved.

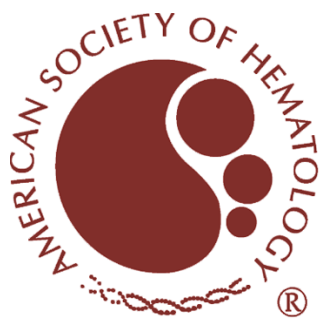




\section{Sustained high-level expression of human factor IX (hFIX) after liver-targeted delivery of recombinant adeno-associated virus encoding the $\mathrm{hFIX}$ gene in rhesus macaques}

Amit C. Nathwani, Andrew M. Davidoff, Hideki Hanawa, Yunyu Hu, Fredric A. Hoffer, Alexander Nikanorov, Clive Slaughter, Catherine Y. C. Ng, Junfang Zhou, Jay N. Lozier, Timothy D. Mandrell, Elio F. Vanin, and Arthur W. Nienhuis

\begin{abstract}
The feasibility, safety, and efficacy of liverdirected gene transfer was evaluated in 5 male macaques (aged 2.5 to 6.5 years) by using a recombinant adeno-associated viral (rAAV) vector (rAAV-2 CAGG-hFIX) that had previously mediated persistent therapeutic expression of human factor IX (hFIX; 6\%$10 \%$ of physiologic levels) in murine models. A dose of $4 \times 10^{12}$ vector genomes $(\mathrm{vgs}) / \mathrm{kg}$ of body weight was administered through the hepatic artery or portal vein. Persistence of the rAAV vgs as circular monomers and dimers and high-molecularweight concatamers was documented in
\end{abstract}

liver tissue by Southern blot analysis for periods of up to 1 year. Vector particles were present in plasma, urine, or saliva for several days after infusion (as shown by polymerase chain reaction analysis), and the vgs were detected in spleen tissue at low copy numbers. An enzyme-linked immunosorption assay capable of detecting between $1 \%$ and $25 \%$ of normal levels of $\mathrm{hFIX}$ in rhesus plasma was developed by using hyperimmune serum from a rhesus monkey that had received an adenoviral vector encoding hFIX. Two macaques having 3 and 40 rAAV genome equivalents/cell, respec- tively, in liver tissue had $4 \%$ and $8 \%$ of normal physiologic plasma levels of hFIX, respectively. A level of $\mathrm{hFIX}$ that was $3 \%$ of normal levels was transiently detected in one other macaque, which had a genome copy number of 25 before abrogation by a neutralizing antibody (inhibitor) to hFIX. This nonhuman-primate model will be useful in further evaluation and development of rAAV vectors for gene therapy of hemophilia B. (Blood. 2002;100:1662-1669)

(๑) 2002 by The American Society of Hematology

\section{Introduction}

Recombinant adeno-associated viral vectors (rAAVs) hold great promise for the treatment of hemophilia B. Preclinical studies in murine and canine models of hemophilia B have demonstrated persistent therapeutic expression of factor IX (FIX) leading to correction of the bleeding phenotype after intramuscular or portal vein administration of rAAV..$^{1-7}$ Liver-targeted delivery of rAAV resulted in significantly higher levels of FIX than observed after intramuscular administration of an equivalent dose of vector in immunodeficient mice. ${ }^{8}$ More important, the development of neutralizing antibodies (NAbs) to human FIX (hFIX) is more common after intramuscular injection of rAAV than after intraportal administration of the same dose of vector. ${ }^{8-11}$ Mice with persistent hFIX expression after liver-targeted delivery of rAAV could not mount a substantial antibody $(\mathrm{Ab})$ response when challenged repeatedly with hFIX antigen in Freund adjuvant, a result suggesting that the liver has a unique ability to induce immune tolerance to neoantigens. ${ }^{12}$ Endothelial cells of the liver, which can efficiently process and cross-present exogenous soluble antigens to $\mathrm{CD} 8^{+} \mathrm{T}$ cells, are intimately involved in antigenspecific immune tolerance after liver-targeted gene transfer with rAAV vectors. ${ }^{13}$

From the Department of Haematology, University College London, United Kingdom; National Blood Authority, United Kingdom; Department of Surgery, Division of Experimental Hematology, Diagnostic Imaging, and Hartwell Center for Bioinformatics and Biotechnology, St Jude Children's Research Hospital, Memphis, TN; Food and Drug Administration Center for Biologics Evaluation and Research, Bethesda, MD; and Department of Comparative Medicine, University of Tennessee Health Science Center, Memphis.

Submitted February 22, 2002; accepted April 30, 2002. Prepublished online as Blood First Edition Paper, May 17, 2002; DOI 10.1182/blood-2002-02-0589.

Supported by the ASSISI Foundation of Memphis (grant 94-00), a Cancer Center Support CORE grant (P30 CA 21765), the Hartwell Center for
The findings of sustained expression of hFIX at therapeutic levels after a single bolus injection of rAAV vector into the portal vein of mice ${ }^{3-6,8}$ and the absence of toxicity after liver-directed delivery of high titers of rAAV vector in murine and canine models of hemophilia led to initiation of a phase 1-2 clinical study. This study, however, has raised concerns about germline transmission because infusion of $2 \times 10^{11}$ vector genomes $(\mathrm{vgs}) / \mathrm{kg}$ of body weight into the hepatic artery resulted in detection of rAAV vgs in the semen of the first adult volunteer with hemophilia B. ${ }^{14}$ Although there was no evidence of transduction of spermatocytes with this low dose of vector particles, therapeutically relevant doses of AAV may lead to germline transmission. The absence of vgs in the semen of hemophilic dogs given an intrahepatic bolus of a 10- to 30-fold higher dose of rAAV than that received by the first adult volunteer ${ }^{15}$ calls into question the value of preclinical safety data derived from murine and canine models. The biodistribution of the vector in these laboratory animals may differ markedly from that in humans, a natural host for the virus from which the vector was derived.

Although hemophilia has not been observed in rhesus macaques, these monkeys, like humans, are a natural host for AAV and

Bioinformatics and Biotechnology, American Lebanese Syrian Associated Charities, the Wellcome Trust, United Kingdom (049894/114; A.C.N.), and the Katharine Dormandy Trust, United Kingdom (A.C.N.).

Reprints: Arthur W. Nienhuis, Experimental Hematology, St Jude Children's Research Hospital, 332 North Lauderdale, Memphis, TN 38105; e-mail: arthur.nienhuis@stjude.org.

The publication costs of this article were defrayed in part by page charge payment. Therefore, and solely to indicate this fact, this article is hereby marked "advertisement" in accordance with 18 U.S.C. section 1734.

(C) 2002 by The American Society of Hematology 
macaque models thus offer a unique opportunity for evaluating the biodistribution, gene-transfer efficiency, and toxicity of rAAV in the context of preceding natural sensitization to AAV. ${ }^{16}$ Results of studies in macaques have consistently predicted clinical outcomes in humans after gene transfer with adenoviral and retroviral vectors. ${ }^{17-24}$ In addition, macaques have a considerably longer lifespan than the commonly used laboratory animals, an important asset for evaluating long-term safety and durability of expression after rAAV-mediated gene transfer. However, difficulties in distinguishing native rhesus FIX from the highly homologous human cognate ${ }^{25}$ have impeded use of macaques for preclinical evaluation of rAAV vector-mediated expression of FIX. We overcame this difficulty to demonstrate stable, high-level transduction of rhesus liver tissue leading to expression of hFIX at therapeutic levels in rhesus plasma for more than a year. Our studies also provided data on the biodistribution and shedding of vector particles in biologic fluids and long-term transduction of distant organs in a context that is relevant to humans.

\section{Methods}

\section{Production and purification of rAAV-hFIX vector}

The pAV CAGG-FIX plasmid encodes hFIX complementary DNA (cDNA) under the control of the cytomegalovirus enhancer, $\beta$-actin promoter complex that was used to generate the rAAV CAGG-FIX vector. ${ }^{8} \mathrm{AAV}$ vector preparations for the studies in rhesus macaques were made by scaling up our previously described adenovirus-free transient transfection method. ${ }^{8}$ Briefly, subconfluent $293 \mathrm{~T}$ cells either in cell factories (Nunc, Roskilde, Denmark) or plated on 15-cm plates were cotransfected with pAV CAGG-FIX vector plasmid, an adenoviral helper plasmid (80-XX6), and a packaging plasmid $(\mathrm{XX} 2)^{26}$ by using the calcium phosphate precipitation method. Cells were harvested 50 to 60 hours after transfection, lysed, and incubated with nuclease before purification by heparin affinity-column chromatography. ${ }^{27}$ Standard slot-blot analysis was used to determine the vector particle titer. Contamination with wild-type AAV was determined by a polymerase chain reaction (PCR) assay. ${ }^{28}$ Aliquots of rAAV were periodically subjected to polyacrylamide gel electrophoresis (PAGE). The vector stocks were consistently free of contamination with wild-type AAV or adenoviral and cellular proteins.

\section{Studies in animals}

All animals were treated according to the standards described in the Guide for Care and Use of Laboratory Animals (National Institutes of Health publication 85-23). All procedures were performed in accordance with institutional guidelines under protocols approved by the Institutional Biosafety Committee and the Institutional Animal Care and Use Committee at St Jude Children's Research Hospital and the University of Tennessee, Memphis. Six captive-bred male Macaca mulatta aged 2.5 to 6.6 years and weighing 1.6 to $7.6 \mathrm{~kg}$ were purchased from Covance Research Products (Alice, TX) and housed in the dedicated primate facility at the University of Tennessee Health Science Center.

A total of $4 \times 10^{12} \mathrm{vgs} / \mathrm{kg}$ rAAV CAGG-FIX vector particles diluted in 40 to $80 \mathrm{~mL}$ phosphate-buffered saline (PBS) was infused into the liver vasculature. The first 2 macaques (monkeys 1 and 2) received a bolus infusion of rAAV CAGG-FIX into the hepatic artery; monkey 3 received 2 fractionated doses of $2 \times 10^{12} \mathrm{vgs} / \mathrm{kg}$ (total dose, $4 \times 10^{12} \mathrm{vgs} / \mathrm{kg}$ ) given 72 hours apart. The macaques were sedated with ketamine $(10 \mathrm{mg} / \mathrm{kg})$. After intubation, anesthesia was maintained with $1.5 \%$ isoflurane. Under sterile conditions, the superficial femoral artery was dissected free through a groin incision. With use of fluoroscopic guidance, a guide wire was introduced to aid manipulation of a catheter ( 3 French) into the common hepatic artery. The location was confirmed angiographically. Saline flushes were used to keep the line patent without heparin. The rAAV CAGG-FIX vector was infused into the hepatic artery during a 15 -minute period, without balloon occlusion to reduce the flow rate. The location of the catheter was again confirmed angiographically on completion of vector infusion, before removal of the catheter. The superficial femoral artery was sutured with 5-0 polypropylene, and the groin wound was closed in layers with 3-0 polygalactin 910 sutures. In monkey 3 , fractionated delivery of rAAV required 2 separate catheterization procedures through the right and left superficial femoral arteries. Postoperatively, the macaques recovered well, without evidence of vascular or neurologic injury.

The same total dose of rAAV CAGG-FIX vector was administered into the portal venous circulation of 2 other macaques either as a bolus infusion (monkey 4) or in 2 fractionated doses of $2 \times 10^{12} \mathrm{vgs} / \mathrm{kg}$ (monkey 5). A limited laparotomy through a midline abdominal incision was performed in macaques anesthetized with isoflurane to gain access to the superior mesenteric vein, into which vector was infused slowly through a 27 -gauge needle. The fractionated infusion of $\mathrm{rAAV}$ in monkey 5 required 2 separate laparotomy procedures through the same midline abdominal incision. All animals recovered well after abdominal surgery.

To provide quality assurance of the high-titer rAAV CAGG-FIX stock prepared for each macaque, $4 \times 10^{12} \mathrm{vgs} / \mathrm{kg}$ derived from each of these vector stocks was injected into the portal vein of C57Bl/6 severe combined immunodeficient mice and shown to have equivalent biologic activity on the basis of the level of hFIX expression, as observed previously. ${ }^{8}$

\section{Enzyme-linked immunosorbent assay (ELISA) for quantitating $\mathrm{hFIX}$ in rhesus plasma}

We initially used an ELISA method described by Lozier et $\mathrm{al}^{25}$ to detect hFIX in rhesus plasma. This method, which relies on commercially available polyclonal Abs against hFIX, was unable to reliably detect levels of hFIX in rhesus plasma below $10 \%$ of physiologic levels because of high background cross-reactivity with endogenous rhesus FIX. We therefore developed an alternative assay using antiserum from a macaque (RQ1305) in which high titers of anti-hFIX Abs developed after adenovirus-mediated gene transfer of a vector encoding the hFIX gene. ${ }^{29}$ This antiserum specifically neutralized hFIX activity ( $>30$ Bethesda inhibitor assay units [BIAUs]) without significantly impairing the function of rhesus FIX.

Flat-bottomed, 96-well plates (Dynatech, Chantilly, VA) were coated with $50 \mu \mathrm{L}$ of a 1:50 dilution of the rhesus antiserum, left overnight at $4^{\circ} \mathrm{C}$, washed with PBS containing 0.05\% Tween 20 (PBST), and blocked with $200 \mu \mathrm{L} /$ well $6 \%$ bovine serum albumin (BSA; Sigma, St Louis, MO) in PBST during a 1-hour incubation at $37^{\circ} \mathrm{C}$. Standards were made by using serial dilutions of rhesus plasma spiked with affinity-purified hFIX (starting concentration, $5000 \mathrm{ng} / \mathrm{mL}$; Sigma). Rhesus samples and standards were diluted 1:5 in PBST containing 2\% BSA, and $50 \mu \mathrm{L}$ was loaded in duplicates. After a 2-hour incubation at room temperature, the plates were washed and incubated for an additional hour with $100 \mu \mathrm{L}$ horseradish peroxidase (HRP)-conjugated goat anti-hFIX polyclonal secondary Ab at a final concentration of $1 \mu \mathrm{g} / \mathrm{mL}$ (Affinity Biologicals, Ancaster, ON, Canada). After a final wash step, plates were developed with o-phenylenediamine dihydrochloride peroxidase substrate (Sigma) and the optical density was assessed spectrophotometrically at $492 \mathrm{~nm}$. Background cross-reactivity from endogenous rhesus FIX was eliminated by coating the plate with a 1:5 dilution of naive rhesus plasma.

\section{Western blot analysis to detect $\mathrm{hFIX}$ in rhesus plasma}

Rhesus plasma from macaques in the experimental and control groups was subjected to the barium citrate precipitation method described previously ${ }^{30}$ to isolate the vitamin $\mathrm{K}$-dependent proteins. Approximately $5 \mu \mathrm{g}$ precipitated protein was loaded on a $10 \%$ sodium dodecyl sulfate-PAGE gel and transferred to a nitrocellulose membrane after electrophoresis. The blots were probed with a 1:50 dilution of rhesus antiserum (from macaque RQ1305) in Tris-(tris(hydroxymethyl)aminomethane)-buffered saline with $0.05 \%$ Tween 20 containing $2 \%$ BSA. After washing, the blots were exposed to an HRP-conjugated rabbit antirhesus $\operatorname{IgG}$ (1:15 000 dilution; Sigma) secondary $\mathrm{Ab}$. The signal was developed with an enhanced chemiluminescence kit (Amersham Biosciences, Arlington Heights, IL). Dilutions of affinity-purified hFIX (Sigma) in rhesus plasma served as a positive control. 


\section{Molecular studies to evaluate rAAV gene-transfer efficiency in macaques}

Wedge-section liver biopsy specimens were obtained from both lobes of the liver between 3 and 12 months after liver-targeted delivery of vector in macaques. Biopsy specimens were also obtained from the spleen, kidney, and testis of monkey 3 at 11 months after fractionated-dose infusion of vector into the hepatic artery. All biopsies were performed with the macaques under isoflurane anesthesia. A portion of the tissue sample was frozen in liquid nitrogen and then pulverized with a mortar and pestle. High-molecular-weight (HMW) DNA was isolated from the residual material by using Genomic-tip 100/G according to the manufacturer's instructions (Qiagen, Valencia, CA). For Southern blot analysis of liver DNA, undigested genomic DNA and DNA digested with NheI (which cuts twice within the vg) or EcoRI (which cuts once within the vg) were electrophoresed through a $0.8 \%$ agarose gel, transferred to a nylon membrane (Hybond $\mathrm{N}+$; Amersham Biosciences), and then hybridized at $42^{\circ} \mathrm{C}$ with an $\alpha$-phosphorus 32-labeled 417-bp fragment from the $3^{\prime}$ end of the hFIX cDNA. The intensity of the hybridization was determined with a STORM PhosphorImager and ImageQuant software (Molecular Dynamics, Sunnyvale, CA).

One $\mu \mathrm{g}$ genomic DNA extracted from the liver, spleen, kidneys, and testis was subjected to PCR using primers that amplified a 512-bp region of the transgene ( $5^{\prime}$ primer, 5'-CTTCCATGAAGGAGGTAGAG-3', located in the $3^{\prime}$ untranslated region of the hFIX cDNA; and $3^{\prime}$ primer, 5'TATGTCCTTCCGAGTGAGAG-3', from the $5^{\prime}$ region of the rabbit $\beta$-globin polyadenylation sequences). PCR conditions were as follows: $94^{\circ} \mathrm{C}$ for 2 minutes followed by 30 cycles at $95^{\circ} \mathrm{C}$ for 30 seconds, $55^{\circ} \mathrm{C}$ for 30 seconds, and $72^{\circ} \mathrm{C}$ for 1 minute and a final extension at $72^{\circ} \mathrm{C}$ for 7 minutes. Standards consisting of serial dilutions of vector DNA in naive genomic DNA from rhesus liver tissue were used to quantitate the proviral copy number. Twenty percent of the samples were electrophoresed on a $1.5 \%$ agarose gel. The integrity of the DNA was determined by amplifying a 604-bp region of the rhesus $\beta$-actin gene with use of the appropriate primers (5' TGACGGGGTCACCCACACTGTGCCCATCTA 3' and 5' CTAGAAGCATTTGC GGTGGACGATGGAGGG $3^{\prime}$ ). The relative intensity of the signal was assessed digitally by using AlphaImager software (version 3.24; Alpha Innotech, San Leandro, CA).

Total RNA was isolated from the liver of control macaques and macaques transduced with rAAV CAGG-FIX by using RNA Stat (Teltest, Friendswood TX). Approximately $1 \mu \mathrm{g}$ total RNA from each sample was subjected to reverse transcription conditions in the presence or absence of reverse transcriptase (RT) by using the first-strand cDNA synthesis kit for RT-PCR (Roche Molecular Biochemicals, Indianapolis, IN). Five microliters of the resulting sample was amplified in a $50-\mu \mathrm{L}$ PCR reaction as described above.

\section{Detection of rAAV genome in body fluids}

Plasma, urine, and saliva (oral-swab) samples were collected from each macaque at 48-hour intervals for 2 weeks after liver-targeted delivery of rAAV CAGG-FIX. Oral swabs were placed in PBS containing 1\% penicillin/streptomycin (Gibco BRL, Gaithersburg, MD) for 30 minutes at room temperature. All 3 types of body fluids were clarified by centrifugation at $15000 \mathrm{rpm}$, filtered through a $0.22-\mu \mathrm{m}$ filter, and divided in aliquots before storage at $-70^{\circ} \mathrm{C}$. One hundred microliters of the samples was incubated with $200 \mu \mathrm{L}$ digestion buffer $(50 \mathrm{mM}$ potassium chloride, $10 \mathrm{mM}$ Tris [pH 8.0], $2.5 \mathrm{mM}$ magnesium chloride, and $0.5 \%$ Tween 20) containing $200 \mu \mathrm{g} / \mathrm{mL}$ proteinase $\mathrm{K}$ (Roche Molecular Biochemicals) at $55^{\circ} \mathrm{C}$ for 3 hours. After 10 minutes at $95^{\circ} \mathrm{C}, 2.5 \mu \mathrm{L}$ of the sample was used in a PCR reaction under the conditions described above. Amplified products were analyzed by agarose-gel electrophoresis. Negative samples were spiked with vector plasmid and subjected to PCR to ensure that the sample did not contain inhibitors of PCR. The sensitivity of the assay was evaluated by incubating a known concentration of rAAV CAGG-FIX (based on slot-blot results) with pretreatment samples of plasma and urine before the viral DNA was extracted and subjected to the PCR conditions described above. This method could reliably detect 500 vector particles in $1 \mathrm{~mL}$ rhesus plasma or urine.

\section{Hematologic and clinical chemistry analyses}

Samples for complete blood counts (CBCs), serum chemistry analyses (blood urea nitrogen and liver-function tests), coagulation-profile determinations (prothrombin and activated partial thromboplastin time [APTT]), and serum interleukin 6 (IL-6) assays were obtained every 48 hours for 2 weeks after vector infusion to assess toxicity. Thereafter, these variables were assessed monthly. The CBCs, serum chemistry analyses, and coagulation-profile determinations were performed by Antech Diagnostics (Southaven, MS). Serum IL-6 levels were assessed with an IL-6 immunoassay kit (R\&D Systems, Minneapolis, MN) used according to the manufacturer's instructions.

\section{Detection of anti-hFIX Abs}

Plasma samples from the macaques were screened for the presence of $\mathrm{Ab}$ against hFIX by using an ELISA described previously. ${ }^{8}$ Briefly, plates were coated with affinity-purified hFIX protein diluted to a concentration of $1 \mu \mathrm{g} / \mathrm{mL}$ with $0.1 \mathrm{M}$ sodium bicarbonate buffer, left overnight, washed, and blocked for 1 hour at $37^{\circ} \mathrm{C}$ with PBST containing 6\% BSA. After washing with PBST, $50-\mu \mathrm{L}$ dilutions of rhesus plasma (1:50, 1:500, and 1:1000) were applied to these wells in duplicate. Abs against hFIX were detected with a 1:40 000 dilution of HRP-conjugated rabbit antirhesus IgG (Sigma). Dilutions of plasma from macaques with anti-hFIX $\mathrm{Ab}^{29}$ (monkeys RQ1305, RQ1234, and 84268) were included as positive controls. The titer of the $\mathrm{Ab}$ was defined as the maximum dilution at which the absorbance at $492 \mathrm{~nm}$ exceeded that of preimmune serum by 0.05 absorbance unit. Additionally, positive samples were subjected to the Bethesda assay as described previously. ${ }^{31}$ Briefly, citrated rhesus test plasma diluted in Owren buffer was incubated with normal pooled human plasma (Sigma) or normal rhesus plasma at $37^{\circ} \mathrm{C}$ for 2 hours. The residual hFIX activity (APTT) was then determined by using a 1-step APTT assay. One Bethesda unit was defined as the reciprocal of the dilution of test plasma at which 50\% of FIX activity was inhibited. The sensitivity of the assay was 1 BIAUs $/ \mathrm{mL}$.

\section{Detection of anti-AAV Abs}

An immune-capture assay was used to detect anti-AAV-specific Abs in rhesus plasma. Briefly, wells in a 96-well plate were coated with $100 \mu \mathrm{L}$ AAV2 antigen $\left(5 \times 10^{10} \mathrm{rAAV} \mathrm{vgs} / \mathrm{mL}\right)$ in $0.1 \mathrm{M}$ sodium bicarbonate buffer, left overnight at $4^{\circ} \mathrm{C}$, washed 5 times with PBST, and blocked with $200 \mu \mathrm{L} 6 \% \mathrm{BSA}$ in PBST for 1 hour at $37^{\circ} \mathrm{C}$. After washing, $50 \mu \mathrm{L}$ appropriately diluted rhesus plasma $(1: 25,1: 250$, and 1:5000 dilutions in PBST) was added to the wells in duplicate. Rhesus IgG Ab against rAAV was detected by using a 1:40000 dilution of HRP-conjugated rabbit antirhesus IgG (Sigma). Since all values were within the linear range, the titer of the Ab was defined arbitrarily as the maximum absorbance at 492 $\mathrm{nm}$ with the 1:5000 dilution of the rhesus serum.

NAb titers were analyzed by determining the ability of rhesus serum to inhibit transduction of $293 \mathrm{~T}$ cells by a reporter virus in which green fluorescent protein was under the control of the CAGG promoter (rAAV CAGG-GFP). Rhesus samples were diluted in PBS (1:50, 1:500, 1:2000, and 1:5000) and incubated for 60 minutes at $37^{\circ} \mathrm{C}$ with $1 \times 10^{9} \mathrm{rAAV}$ CAGG-GFP particles in a total volume of $250 \mu \mathrm{L}$ in 12 -well plates. The mix of virus and serum was then added to $1 \times 10^{5} 293 \mathrm{~T}$ cells/well in 12-well plates. After overnight incubation, the cells were washed twice with PBS and cultured for an additional 48 hours before evaluation of transfection efficiency by flow cytometry. The NAb titer was calculated arbitrarily as the highest dilution that inhibited transduction of $293 \mathrm{~T}$ cells by $50 \%$.

\section{Results}

\section{Development of an assay for distinguishing hFIX in rhesus plasma}

The close homology of the rhesus FIX protein with its human cognate $(\sim 97 \% \text { identity })^{25}$ posed a major challenge to reliable and selective detection of hFIX in rhesus plasma. Previous studies 
A

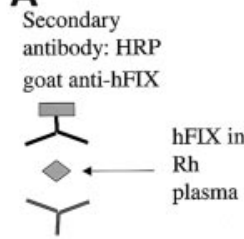

Capture antibody: Rh immuneserum
B
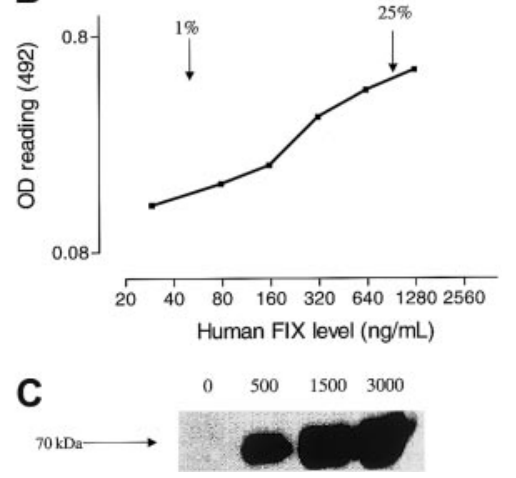

Figure 1. Detection of $\mathrm{hFIX}$ in rhesus plasma. (A) Schematic representation of ELISA in which hFIX in rhesus plasma was captured by anti-hFIX Abs (capture Ab). The level of hFIX antigen was then determined with an HRP-conjugated goat anti-hFIX polyclonal secondary Ab. (B) A typical standard curve obtained with our ELISA showing a relatively linear range for detection of hFIX above $1 \%$ to $25 \%$ of normal levels. (C) Western blot analysis. Rhesus plasma was spiked with a known concentration of $\mathrm{hFIX}(0-3000 \mathrm{ng} / \mathrm{mL})$. The vitamin $\mathrm{K}$-dependent proteins were then precipitated by using barium citrate, and $5 \mu \mathrm{g}$ precipitated protein was analyzed by a Western blotting procedure using rhesus immune serum (RQ1305) as the primary Ab. A band $(\sim 70 \mathrm{kDa})$ in the expected position for FIX on reducing gels was detected only in rhesus plasma spiked with hFIX.

using adenoviral vectors resulted in high titers of anti-hFIX Abs in rhesus macaques that specifically neutralized hFIX activity $(>30$ BIAUs) without significantly impairing the function of rhesus FIX. ${ }^{29}$ When antiserum from one of these macaques (RQ1305) was incubated with rhesus plasma spiked with various amounts of affinity-purified hFIX in the context of an immune-capture ELISA, we were able to reliably detect $1 \%$ to $25 \%$ hFIX in rhesus plasma (Figure 1B). The specificity of the antiserum was further demonstrated by Western blot analysis in which a prominent 70-kDa band, the expected position for hFIX on a nonreducing protein gel, was detected in a dose-dependent fashion in rhesus plasma spiked with hFIX (Figure 1C).

\section{Stable transduction and expression of $\mathrm{hFIX}$ after liver-targeted delivery of rAAV particles in rhesus macaques}

Vector particles were generated by scale-up of the transient transfection and heparin affinity-column chromatography purification procedures described previously. ${ }^{8}$ Before injection in rhesus macaques, each vector preparation was shown to have anticipated biologic activity in studies in immunodeficient mice (data not shown). The results of liver-targeted administration of rAAV CAGG-FIX in macaques are shown in Table 1. The first 2 macaques received a single bolus infusion into the common hepatic artery with use of interventional radiologic techniques. Both animals had a 2- to 10-fold elevation in levels of transaminases during the 7 to 10 days after the infusion (data not shown). This may have been related to the radiologic technique, since such elevations were not observed after vector administration in the third monkey given an hepatic artery infusion or in the 2 monkeys given the vector through the portal vein (monkeys 4 and 5).

The hFIX levels in the 5 macaques studied are shown in Figure 2. It is noteworthy that the levels in the first 2 monkeys, which received a single bolus infusion through the hepatic artery, were detectable at approximately $1 \%$ physiologic levels for several weeks but then remained undetectable thereafter. However, monkey 3 , in which the total dose of vector particles $\left(4 \times 10^{12} \mathrm{vgs} / \mathrm{kg}\right)$ was divided into 2 equal doses given 3 days apart, had levels of hFIX of $3 \%$ to $4 \%$ for more than a year. The highest levels of hFIX ( $8 \%$ to $10 \%$ of the physiologic range) were observed in monkey 4 , which received a single bolus infusion of vector particles through the portal vein. The fifth monkey, which received 2 divided doses of vector particles through the portal vein, had detectable levels of hFIX for only 4 to 5 weeks. After this time, hFIX was abrogated by the presence of a specific anti-hFIX inhibitor ( $>1: 1000$ on ELISA and 12 BIAUs/mL on Bethesda assay at 4 months), which did not cross-react with rhesus FIX. Whether the differences in the levels of hFIX among monkeys 1 to 4 were related to technique, the route or schedule of administration, the genetic diversity of these outbred animals, or a combination of these factors is unknown.

Liver biopsy specimens were obtained at various intervals from all macaques and assessed by using Southern blot analysis. The overall copy number of the vgs in liver cells ranged from less than 1 (monkeys 1 and 2) to approximately 40 (monkey $4,4 \times 10^{5}$ copies/ $\mu \mathrm{g}$ of genomic DNA) and approximately paralleled the levels of hFIX observed in plasma from these monkeys (Table 1). DNA species corresponding to circular monomers, linear monomers, circular dimers, and HMW concatamers-most of which were present in a head-to-tail configuration, although a small proportion was present in a head-to-head configuration-were detected in monkeys 3 and 4 (Figure 3). Because the monomer form was converted to a linear form on digestion with EcoRI, we assume that it was episomal. The integration status of the HMW concatamers could not be determined from our analyses. RT-PCR analysis confirmed expression of the hFIX transgene at levels roughly reflecting the genome copy numbers in individual monkeys (data not shown).

\section{Dissemination and shedding of virus and humoral response to viral capsid after liver-targeted delivery of vector particles}

A PCR assay having a sensitivity of at least 500 genomes (particles)/mL was used to detect vector sequences in body fluids (plasma, urine, and saliva) from monkeys 1 to 4 for 12 days after vector infusion (Figure 4). Varying vg amounts were detected in plasma from all monkeys for 3 days after vector administration. In monkey 3 , which received 2 infusions of vector particles separated by 72 hours, vgs were detected in plasma for 6 days. The vgs were present in urine and saliva from monkey 1 and urine from monkey

Table 1. Gene transfer after liver-targeted delivery of rAAV CAGG-FIX in rhesus macaque monkeys

\begin{tabular}{|c|c|c|c|c|c|c|c|}
\hline Monkey & $\begin{array}{l}\text { Weight, } \\
\text { kg }\end{array}$ & $\begin{array}{l}\text { Delivery } \\
\text { route }\end{array}$ & Infusion* & $\begin{array}{l}\text { Transgene copy } \\
\text { no./diploid genome }\end{array}$ & $\begin{array}{c}\text { Maximum hFIX expression } \\
\text { (\% of normal) }\end{array}$ & $\begin{array}{l}\text { Anti-hFIX } \\
\text { Abs }\end{array}$ & $\begin{array}{c}\text { Duration of } \\
\text { expression, wks }\end{array}$ \\
\hline 1 & 4.6 & $\mathrm{HA}$ & 1 & 0.05 & 0.8 & No & $<15$ \\
\hline 2 & 4.6 & $\mathrm{HA}$ & 1 & 0.1 & 1.0 & No & $<15$ \\
\hline 3 & 2.2 & $\mathrm{HA}$ & 2 & 3.2 & 4 & No & $>50$ \\
\hline 4 & 3.8 & PV & 1 & 40 & 10 & No & $>40$ \\
\hline 5 & 7.6 & PV & 2 & 25 & 3 & Yes & $<3$ \\
\hline
\end{tabular}

HA indicates hepatic artery; and PV, portal vein.

*Vector particles $\left(4 \times 10^{12} \mathrm{vgs} / \mathrm{kg}\right.$ ) were given either as 1 infusion or in 2 equal divided doses separated by 3 days. 
A
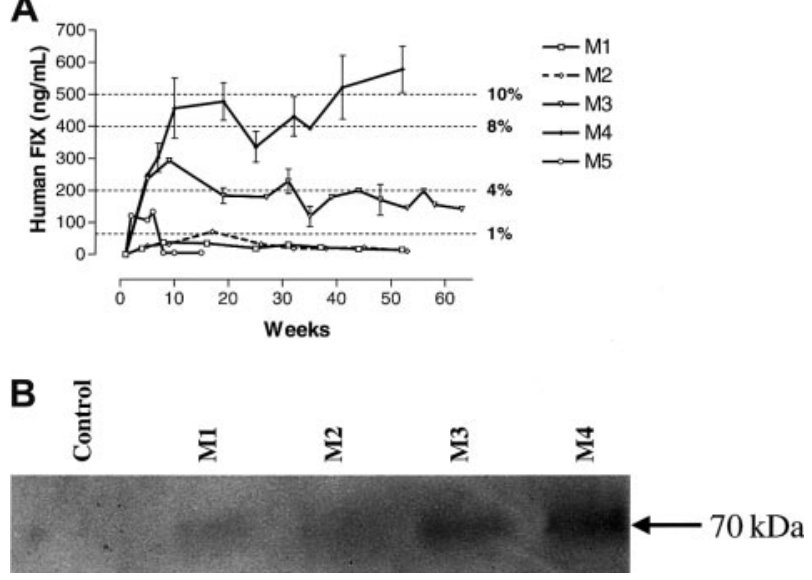

Figure 2. Expression of $\mathrm{hFIX}$ in rhesus macaques after liver-targeted delivery of rAAV CAGG-FIX. (A) ELISA assay. The hFIX concentration in rhesus plasma was determined at the indicated times after liver-directed administration of rAAV CAGGFIX in 5 rhesus macaques (M1, $\square$; M2, - $\diamond--;$ M3, $\nabla ;$ M4, $\diamond$; and M5, $\bigcirc)$. Samples from monkeys 1 to 4 were evaluated independently on 4 occasions; those from monkey 5 were assessed on 2 separate occasions. Results are means \pm SEM. (B) Western blot analysis of barium citrate precipitated rhesus serum samples.

2 but in neither urine nor saliva from monkeys 3 and 4 . Negative samples were spiked with vector plasmid and subjected to PCR to demonstrate the absence of inhibitors of PCR in the body fluids.

Other than the transient elevations in levels of transaminases in monkeys 1 and 2, all laboratory values, including those for IL-6, remained normal. Low titers of anti-AAV Abs were detected by ELISA in monkeys 1 to 4 before vector infusion at dilutions of 1:25 (monkeys 3 and 4) or 1:100 (monkeys 1 and 2). However, these binding Abs did not function as NAbs, as indicated by their inability to block transduction of $293 \mathrm{~T}$ cells by a reporter vector

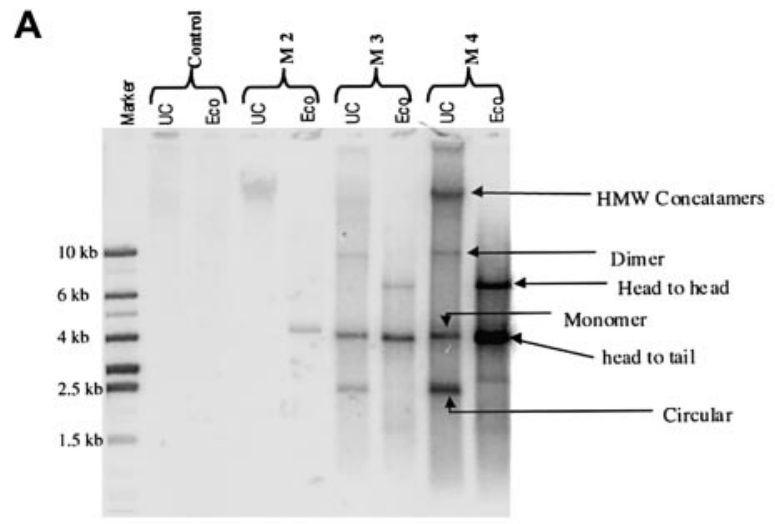

B

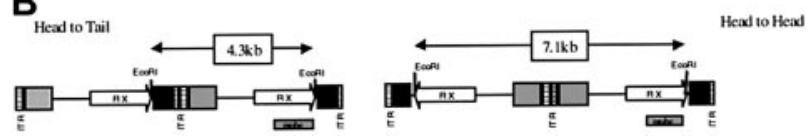

Figure 3. Status of rAAV genome in rhesus liver after rAAV-mediated gene transfer. (A) Southern blot analysis of DNA derived from liver biopsy specimens from monkey 2 (M2), monkey 3 (M3), and monkey 4 (M4) at 11, 9, and 6 months after liver-targeted delivery of rAAV CAGG-FIX. Each lane contains $10 \mu \mathrm{g}$ uncut (UC) DNA or DNA digested with EcoRI, which cuts once within the transgene. The rAAV transgene was not detectable in DNA from the liver of a naive macaque (control). Four different rAAV species were detected in UC genomic DNA from the livers of monkeys 3 and 4 , and these were deduced to represent HMW concatamers as well as double-stranded dimer, monomer, and circular forms (arrows). The EcoRI digest indicated that the rAAV transgene persists mainly as head-to-tail tandems with approximately a third maintained in the head-to-head orientation. (B) Schematic representation of the rAAV CAGG-FIX vector showing the position of the probe and the expected fragment size after EcoRI digestion of the vector.

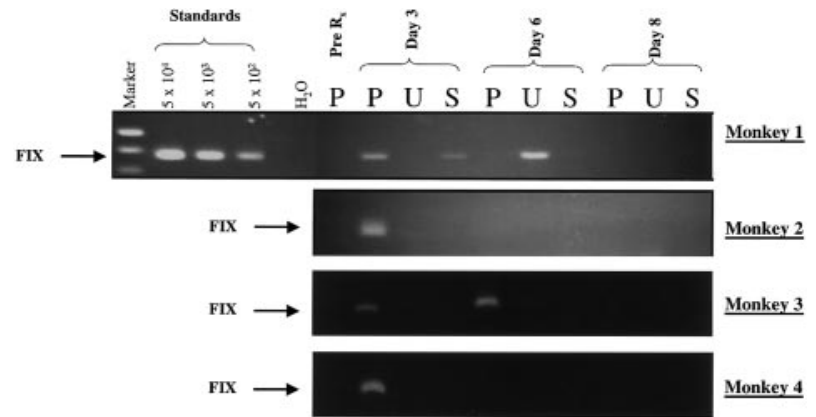

Figure 4. Virus shedding after administration of rAAV in rhesus macaques. A PCR-based assay was used to detect vector sequences in plasma $(P)$, urine $(U)$, and saliva (S) collected from monkeys 1 to 4 on the stipulated days after liver-targeted delivery of rAAV CAGG-FIX. The PCR primers were chosen specifically to amplify a 512-bp hFIX transgene-specific product (arrow labeled FIX). Standards consisting of serial dilutions of rAAV CAGG-FIX in rhesus plasma were used to define the sensitivity of the assay. Twenty percent of the samples were electrophoresed on a $1.5 \%$ agarose gel. Negative samples were spiked with vector plasmid and subjected to $\mathrm{PCR}$ to ensure that the sample did not inhibit the PCR reaction.

rAAV CAGG-EGFP. Vector infusion led to a robust anti-AAV binding IgG response in all 4 macaques after a lag period of 5 and 7 days and coincided with clearance of vector particles from body fluids (Figure 5A). In parallel, there was an increase in the titer of NAbs, which reached peak levels by 3 weeks (Figure 5B). The $\mathrm{NAb}$ titers were sustained at maximum levels for an additional 5 weeks before decreasing to undetectable levels by 12 weeks. In contrast, anti-AAV IgG Ab titers persisted at high levels for more than 250 days in all 4 monkeys assessed.

\section{Analysis of spread of rAAV CAGG-FIX to distant organs}

There was no evidence of inflammation or dysplasia on histopathological analysis of liver, spleen, kidney, or testes tissue from

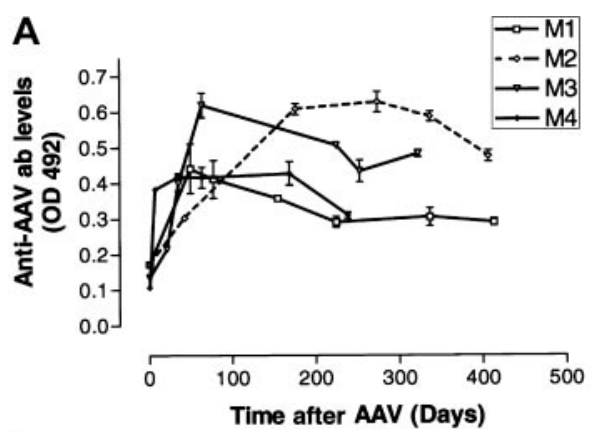

B

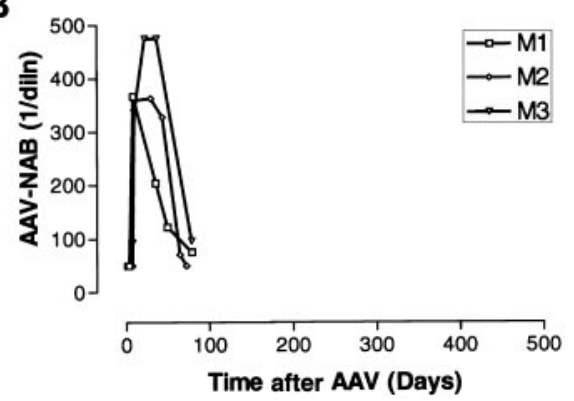

Figure 5. Humoral response to rAAV vector particles. (A) Plasma obtained from monkeys 1 to 4 (same symbols as in Figure 2) was analyzed for the presence of AAV2-specific IgG by ELISA at various times after liver-directed administration of rAAV CAGG-FIX. Results are expressed as the maximum absorbance at $492 \mathrm{~nm}$ with the 1:5000 dilution of the rhesus serum. (B) The NAb titer was assessed by defining the highest dilution of rhesus plasma from monkeys 1 to 3 (same symbols as in Figure 2) that inhibited transduction of $293 \mathrm{~T}$ cells with a reporter virus by $50 \%$. 
monkey 3. Genomic DNA from each type of tissue was subjected to PCR analysis using vector-specific primers that amplified a 512-bp region from the $3^{\prime}$ end of the rAAV CAGG-FIX expression cassette. As expected, rAAV CAGG-FIX sequences were found in the liver, with an average of 2 vector copy numbers/diploid genomic equivalent (Figure 6). Vector sequences were also detected in the spleen $(\sim 0.005$ copies/diploid genome $)$, whereas the kidneys and gonads were consistently negative (detection threshold, $<0.001$ transgene copies/diploid genome).

\section{Discussion}

In this study, we examined the safety and efficacy of liver-targeted delivery of $4 \times 10^{12} \mathrm{vgs} / \mathrm{kg}$ rAAV CAGG-FIX vector particles given to 5 rhesus macaques with use of different routes and schedules of administration. Using an assay developed to specifically detect hFIX in rhesus plasma, we observed stable expression of hFIX at therapeutic levels for more than a year in 2 of 5 macaques. Another macaque initially had therapeutic levels of hFIX, although a specific NAb subsequently developed. We also documented highly efficient transduction of the liver at the genomic level in these 3 macaques, with persistence of the rAAV transgene as HMW concatameric forms as well as smaller episomal forms. Liver-targeted administration of rAAV was well tolerated, even though viral particles were readily detected in plasma and other body fluids for approximately 3 to 6 days after infusion of the vector. An analysis of abdominal organs and the testis found that apart from the liver, the spleen was the only organ with stable persistence of the rAAV transgene.

The copy numbers of the rAAV genome in the 2 macaques that received $4 \times 10^{12} \mathrm{vgs} / \mathrm{kg}$ vector particles through the portal vein were 40/diploid genome and 25/diploid genome for the single dose and split dose, respectively. These values are more than 10-fold higher than the copy number in mice ( 0.65 copies/diploid genome) given an equivalent dose of vector particles. $^{8}$ If these rAAV genomes are distributed to a small subset of hepatocytes, as occurs in mice, ${ }^{32}$ the copy number in some hepatocytes may be quite high ( $>500 /$ cell). Additional studies are needed to validate this potentially important biologic advantage for rAAV vectors in primates. If confirmed, this advantage may allow administration of a lower dose of vector particles. Of interest is the fact that the levels of hFIX in the macaque with 40 copies/diploid genome were
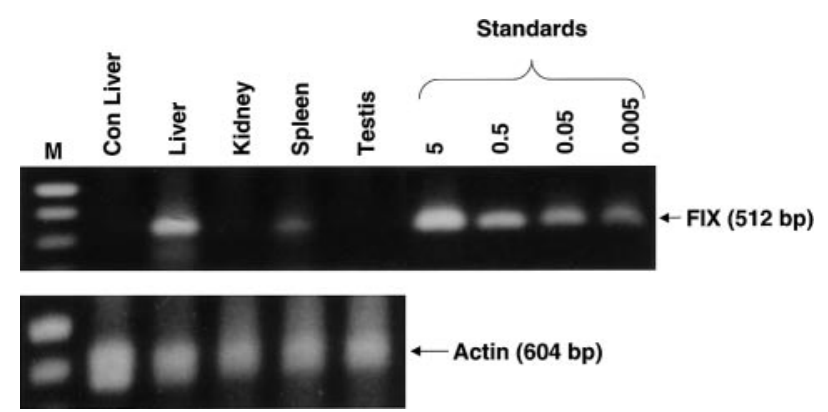

Figure 6. Detection of rAAV CAGG-FIX transgene in extrahepatic tissue. Genomic DNA was extracted from liver, kidney, spleen, and testis tissue from one macaque (monkey 3) 9 months after liver-targeted delivery of rAAV in 2 fractionated doses and from the liver of a naive macaque (Con). Then, $1 \mu \mathrm{g}$ genomic DNA was used for PCR amplification employing transgene-specific primers designed to amplify a 521-bp product. Proviral copy number was deduced from standards that consisted of serial dilutions of vector DNA $\left(5 \times 10^{-3}\right.$ to 5 copies $)$ in $1 \mu \mathrm{g}$ control genomic DNA. The integrity of DNA was determined by amplifying a 604-bp region of the rhesus $\beta$-gene and is shown at the bottom of the panel. estimated to be only about 2-fold higher than levels in mice with 0.65 copies/diploid genome, a discordance that also needs further investigation. At high copy numbers, some factor other than genome number may limit hFIX production. On the other hand, because the assays used in the murine and rhesus models employ different Abs for capture of hFIX and different conditions to reduce background, direct comparison of the absolute levels in the 2 species is difficult.

Transduction of the liver after bolus infusion of an equivalent dose of vector into the hepatic artery of monkeys 1 and 2 was poor, leading to subtherapeutic levels of hFIX in rhesus plasma. The vector preparations administered to monkeys 1 to 3 were different, although they were shown to have equivalent biologic activity in mice and therefore differences between them did not produce the difference in transduction efficiency. ${ }^{8}$ Perhaps noteworthy is the fact that monkeys 1 and 2 had the highest titers of capsid-binding Abs before infusion of the vector particles. These monkeys also had liver toxicity immediately after administration of the vector, which raises the possibility that the transduced hepatocytes were lost during this acute inflammatory insult. Hepatotoxicity has not been observed in mice ${ }^{3,5,8}$ or dogs ${ }^{4,6}$ after liver-targeted delivery of rAAV, and the precise cause of this complication in these 2 macaques, which did not occur in the 3 other macaques we studied, remains unknown. There was no evidence of a humoral response to either vector particles or the transgene product during this acute episode, and T-lymphocyte-mediated cytotoxicity is not a feature of rAAV transduction, unlike gene transfer with naked DNA and adenoviral vectors. ${ }^{33-35}$ Cytotoxic T-lymphocytes (CTLs) to the transgene product or rAAV capsid proteins have not been observed in humans or animal models in the absence of coinfection with adenovirus. ${ }^{35,36}$ In addition, we readministered rAAV-2 into monkey 2 through the portal vein without producing liver damage or an inflammatory response (A.C.N., A.M.D., A.W.N., unpublished data, January 15, 2002), a finding that suggests that CTLs were probably not responsible for the hepatitis in this macaque.

The development of NAbs against hFIX in monkey 5 represents a serious adverse event that was not anticipated on the basis of results in murine and canine studies. These animal models have provided substantial evidence supporting the ability of the liver to induce immune tolerance to neoantigens. ${ }^{8,9,12,13,37,38}$ Formation of NAbs (or inhibitors) is a recognized complication of protein-based therapy for hemophilia. ${ }^{39}$ The incidence after gene therapy may be different than that with protein administration, since the endogenously expressed transgene product is likely to be presented in the context of the major histocompatibility complex (MHC) class I pathway as well as the class II pathway, in contrast to protein concentrates, from which the antigen is presented through the MHC class II pathway. We speculate that the repeated surgical insult primed the rhesus $\mathrm{T}$ cells to mediate formation of anti-hFIX Abs in monkey 5. However, the relative contribution of other factors, such as the monkey's genetic composition, older age, and possible vector extravasation during infusion to the formation of the FIX inhibitor in the context of gene transfer, must be defined. Management of inhibitors involves constant exposure to the offending antigen. ${ }^{40}$ It is possible that sustained transgene expression after gene therapy will induce tolerance to hFIX in monkey 5, but the inhibitor titer remained elevated $(24 \mathrm{BIAUs} / \mathrm{mL})$ at 5 months. A study in a canine hemophilia model also found a neutralizing anticanine FIX Ab in 1 of 4 dogs with a null mutation in the FIX gene. ${ }^{41}$

Our use of a fractionated-dose schedule in 2 macaques was based on the observations by Miao et $\mathrm{al}^{32}$ that the subset of 
hepatocytes susceptible to transduction in mice changes during 2 to 3 days; thus, administration of rAAV at intervals results in persistence of the transgene in distinct populations of hepatocytes. Our goal of augmenting the level of hFIX was achieved when 2 injections were given through the hepatic artery to monkey 3 , in which hFIX levels higher than those in monkeys 1 and 2 were observed, but as noted above, the values in the latter 2 monkeys may have been artificially low because of technical difficulties. When the portal route was used, the genome copy number was found to be lower in the monkey that received the split dose (monkey 5) than in the monkey given the single dose (monkey 4). Because of the possible role of repeated surgical trauma in the development of the hFIX inhibitor in monkey 5, we will use the single-dose regimen in future studies.

Southern blot analysis indicated that a marked proportion of the rAAV transgene was maintained episomally, even at 6 to 9 months after administration of the vector. Previous studies in mice suggested that these episomally maintained rAAV genomes make an important contribution to stable expression. ${ }^{42}$ These observations raise concerns that $\mathrm{rAAV}$-mediated transgene expression may be lost over time because of a low but constant turnover of hepatocytes, as was observed after AAV-mediated gene transfer into skeletal muscle in nonhuman primates. ${ }^{43}$ If expression is lost, readministration of AAV2 may be problematic because macaques have a robust immune response to $\mathrm{rAAV}$ particles that persists for more than a year. However, the ability of these anti-AAV Abs to inhibit transduction by rAAV in an in vitro assay appeared to be limited to 3 to 6 months, suggesting that readministration of AAV2 after this period might lead to efficient transduction in vivo.
Our studies demonstrated the feasibility of achieving sustained expression of therapeutic levels of hFIX for more than a year after liver-targeted delivery of rAAV vector in a nonhuman-primate model and identified several critical issues to be addressed in future studies. These include the relation between genome copy number and hFIX levels, the duration of hFIX production at therapeutic levels, the importance of the immune response to vector capsid proteins with respect to the potential of readministration of vector particles for re-establishing or augmenting hFIX production, the relative merits of hepatic artery and portal vein administration, the incidence of inhibitory Abs to hFIX, and the potential for germline transmission of the vg. Although we support initiation of a clinical trial on the basis of current knowledge, ${ }^{44}$ concomitant studies in nonhuman-primate models are needed to provide critical information necessary to guide the development of future clinical trials. Such nonhuman-primate studies are likely to be expensive and labor intensive, but the investment is justifiable given the risks involved in gene-therapy approaches and the benefits to be gained from success.

\section{Acknowledgments}

We thank Jean Johnson for outstanding assistance in preparation of the manuscript and Dr Mildred Randolph, Department of Comparative Medicine at the University of Tennessee, Health Sciences Center, Memphis, for support.

\section{References}

1. Herzog RW, Hagstrom JN, Kung SH, et al. Stable gene transfer and expression of human blood coagulation factor IX after intramuscular injection of recombinant adeno-associated virus. Proc Nat Acad Sci U S A. 1997:94:5804-5809.

2. Herzog RW, Yang EY, Couto LB, et al. Long-term correction of canine hemophilia $B$ by gene transfer of blood coagulation factor IX mediated by adeno-associated viral vector. Nat Med. 1999;5: 56-63.

3. Snyder RO, Miao CH, Patijn GA, et al. Persistent and therapeutic concentrations of human factor IX in mice after hepatic gene transfer of recombinant AAV vectors. Nat Genet. 1997;16:270-276.

4. Snyder RO, Miao C, Meuse L, et al. Correction of hemophilia $B$ in canine and murine models using recombinant adeno-associated viral vectors. Nat Med. 1999;5:64-70.

5. Wang L, Takabe K, Bidlingmaier SM, III CR, Verma IM. Sustained correction of bleeding disorder in hemophilia B mice by gene therapy. Proc Natl Acad Sci U S A. 1999;96:3906-3910.

6. Wang L, Nichols TC, Read MS, Bellinger DA, Verma IM. Sustained expression of therapeutic level of factor IX in hemophilia B dogs by AAVmediated gene therapy in liver. Mol Ther. 2000;1: 154-158.

7. Chao H, Samulski R, Bellinger D, Monahan $P$, Nichols T, Walsh C. Persistent expression of canine factor IX in hemophilia B canines. Gene Ther. 1999;6:1695-1704.

8. Nathwani AC, Davidoff A, Hanawa H, Zhou J, Vanin EF, Nienhuis AW. Factors influencing in vivo transduction by recombinant adeno-associated viral vectors expressing the human factor IX cDNA. Blood. 2001;97:1258-1265.

9. Ge Y, Powell S, van Roey M, McArthur JG. Factors influencing the development of an anti-facto IX (FIX) immune response following administra- tion of adeno-associated virus FIX. Blood. 2001; 97:3733-3737.

10. Herzog RW, Mount JD, Arruda VR, High KA, Lothrop CD Jr. Muscle-directed gene transfer and transient immune suppression result in sustained partial correction of canine hemophilia B caused by a null mutation. Mol Ther. 2001;4:192-200.

11. Fields PA, Arruda VR, Armstrong E, et al. Risk and prevention of anti-factor IX formation in AAVmediated gene transfer in the context of a large deletion of F9. Mol Ther. 2001;4:201-210.

12. Mingozzi F, Arruda VR, Liu YL, et al. Induction of immunological tolerance to a coagulation factor antigen by hepatic gene transfer [abstract]. Blood. 2001;98:694a.

13. Limmer A, Ohl J, Kurts C, et al. Efficient presentation of exogenous antigen by liver endothelial cells to $\mathrm{CD} 8^{+} \mathrm{T}$ cells results in antigen-specific T-cell tolerance. Nat Med. 2000;6:1348-1354.

14. Boyce N. Trial halted after gene shows up in semen. Nature. 2001;414:677.

15. Arruda VR, Fields PA, Milner R, et al. Lack of germline transmission of vector sequences following systemic administration of recombinant AAV-2 vector in males. Mol Ther. 2001;4:586-592.

16. Samulski RJ, Zhu X, Xiao X, et al. Targeted integration of adeno-associated virus (AAV) into human chromosome 19. EMBO J. 1991;10:39413950.

17. McCluskie MJ, Brazolot Millan CL, Gramzinski $\mathrm{RA}$, et al. Route and method of delivery of DNA vaccine influence immune responses in mice and non-human primates. Mol Med. 1999;5:287-300.

18. Vaughan HA, Ho DW, Karanikas V, Sandrin MS, McKenzie IF, Pietersz GA. The immune response of mice and cynomolgus monkeys to macaque mucin 1-mannan. Vaccine. 2000;18:3297-3309.

19. Donahue RE, Kessler SW, Bodine D, et al. Helper virus induced T cell lymphoma in nonhuman pri- mates after retroviral mediated gene transfer. $J$ Exp Med. 1992;176:1125-1135.

20. Dunbar CE, Tisdale J, Yu JM, et al. Transduction of hematopoietic stem cells in humans and in nonhuman primates. Stem Cells. 1997;15(suppl 1):135-139.

21. Raper SE, Haskal ZJ, Ye X, et al. Selective gene transfer into the liver of non-human primates with E1-deleted, E2A-defective, or E1-E4 deleted recombinant adenoviruses. Hum Gene Ther. 1998; 9:671-679.

22. Crystal RG, McElvaney NG, Rosenfeld MA, et al. Administration of an adenovirus containing the human CFTR cDNA to the respiratory tract of individuals with cystic fibrosis. Nat Genet. 1994;8: 42-51.

23. Bellon G, Michel-Calemard L, Thouvenot D, et al. Aerosol administration of a recombinant adenovirus expressing CFTR to cystic fibrosis patients: a phase I clinical trial. Hum Gene Ther. 1997;8:1525.

24. Donahue RE, Dunbar CE. Update on the use of nonhuman primate models for preclinical testing of gene therapy approaches targeting hematopoietic cells. Hum Gene Ther. 2001;12:607-617.

25. Lozier JN, Metzger ME, Donahue RE, Morgan $R A$. The rhesus macaque as an animal model for hemophilia B gene therapy. Blood. 1999;93:18751881.

26. Xiao X, Li J, Samulski RJ. Production of high-titer recombinant adeno-associated virus vectors in the absence of helper adenovirus. J Virol. 1998; 72:2224-2232.

27. Clark KR, Liu X, McGrath JP, Johnson PR. Highly purified recombinant adeno-associated virus vectors are biologically active and free of detectable helper and wild-type viruses. Hum Gene Ther. 1999;10:1031-1039.

28. Nathwani AC, Hanawa $\mathrm{H}$, Vandergriff J, Kelly $\mathrm{P}$, Vanin EF, Nienhuis AW. Efficient gene transfer 
From www.bloodjournal.org at UCL Library Services on September 15, 2008. For personal use only.

into human cord blood $\mathrm{CD} 34^{+}$cells and the $\mathrm{CD} 34^{+} \mathrm{CD} 38^{-}$subset using highly purified recombinant adeno-associated viral vector preparations that are free of helper virus and wild-type AAV. Gene Ther. 2000;7:183-195.

29. Lozier JN, Metzger ME, Donahue RE, Morgan RA. Adenovirus-mediated expression of human coagulation factor IX in the rhesus macaque is associated with dose-limiting toxicity. Blood. 1999;94:3968-3975.

30. Kemball-Cook G, Johnson DJ, Takamiya O, Banner DW, McVey JH, Tuddenham EG. Coagulation factor VII Gln100 $\rightarrow$ Arg: amino acid substitution at the epidermal growth factor 2-protease domain interface results in severely reduced tissue factor binding and procoagulant function. J Biol Chem. 1998;273:8516-8521.

31. Kung SH, Hagstrom JN, Cass D, et al. Human factor IX corrects the bleeding diathesis of mice with hemophilia B. Blood. 1998;91:784-790.

32. Miao CH, Nakai H, Thompson AR, et al. Nonrandom transduction of recombinant adenoassociated virus vectors in mouse hepatocytes in vivo: cell cycling does not influence hepatocyte transduction. J Virol. 2000;74:3793-3803.

33. Jooss K, Yang Y, Fisher KJ, Wilson JM. Trans- duction of dendritic cells by DNA viral vectors directs the immune response to transgene products in muscle fibers. J Virol. 1998;72:4212-4223.

34. Xiao W, Chirmule N, Schnell MA, Tazelaar J, Hughes JV, Wilson JM. Route of administration determines induction of T-cell-independent humoral responses to adeno-associated virus vectors. Mol Ther. 2000;1:323-329.

35. Chirmule N, Propert K, Magosin S, Qian Y, Qian $\mathrm{R}$, Wilson J. Immune responses to adenovirus and adeno-associated virus in humans. Gene Ther. 1999;6:1574-1583.

36. Hernandez Y, Wang J, Kearns WG, Loiler S, Poirier A, Flotte TR. Latent adeno-associated virus infection elicits humoral but not cell-mediated immune responses in a nonhuman primate model. J Virol. 1999;73:8549-8558.

37. Gutgemann I, Fahrer AM, Altman JD, Davis $\mathrm{MM}$, Chien $\mathrm{YH}$. Induction of rapid T cell activation and tolerance by systemic presentation of an orally administered antigen. Immunity. 1998; 8:667-673.

38. Sun J, Dirden-Kramer B, Ito K, Ernst PB, Van Houten N. Antigen-specific T cell activation and proliferation during oral tolerance induction. $\mathrm{J} \mathrm{Im}$ munol. 1999;162:5868-5875.
39. Nathwani AC, Tuddenham EG. Epidemiology of coagulation disorders. Baillieres Clin Haematol. 1992;5:383-439.

40. Hay CR, Baglin TP, Collins PW, Hill FG, Keeling DM. The diagnosis and management of factor VIII and IX inhibitors: a guideline from the UK Haemophilia Centre Doctors' Organization (UKHCDO). Br J Haematol. 2000;111:78-90.

41. Mount JD, Herzog RW, Tillson M, et al. Sustained phenotypic correction of hemophilia B dogs with a factor IX null mutation by liver-directed gene therapy. Blood. 2002;99:2670-2676.

42. Nakai H, Yant SR, Storm TA, Fuess S, Meuse L, Kay MA. Extrachromosomal recombinant adenoassociated virus vector genomes are primarily responsible for stable liver transduction in vivo. J Virol. 2001;75:6969-6976.

43. Chirmule N, Xiao W, Truneh A, et al. Humoral immunity to adeno-associated virus type 2 vectors following administration to murine and nonhuman primate muscle. J Virol. 2000;74:2420-2425.

44. Nakai H, Ohashi K, Arruda V, et al. A proposed rAAV-liver directed clinical trial for hemophilia B [abstract]. Blood. 2000;96:798a. 